NATIONAL LABORATORY

MANAGED BY UT-BATTELLE

FOR THE DEPARTMENT OF ENERGY

\title{
CORONA and MOTOR VOLTAGE INTERIM REPORT
}

\author{
J. S. Hsu \\ C. L. Coomer \\ S. L. Campbell \\ Oak Ridge National Laboratory
}

Publication Date: April 2005

Prepared by the

OAK RIDGE NATIONAL LABORATORY

Oak Ridge, Tennessee 37831

managed by

UT-BATTELLE, LLC

for the

UT-BATTELLE

U.S. DEPARTMENT OF ENERGY

Under contract DE-AC05-00OR22725 
This report was prepared as an account of work sponsored by an agency of the United States Government. Neither the United States Government nor any agency thereof, nor any of their employees, makes any warranty, express or implied, or assumes any legal liability or responsibility for the accuracy, completeness, or usefulness of any information, apparatus, product, or process disclosed, or represents that its use would not infringe privately owned rights. Reference herein to any specific commercial product, process, or service by trade name, trademark, manufacturer, or otherwise, does not necessarily constitute or imply its endorsement, recommendation, or favoring by the United States Government or any agency thereof. The views and opinions of authors expressed herein do not necessarily state or reflect those of the United States Government or any agency thereof. 


\section{CONTENTS}

Page

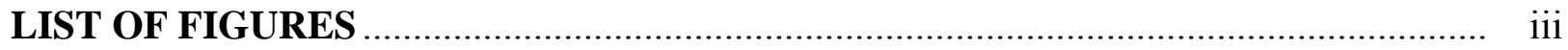

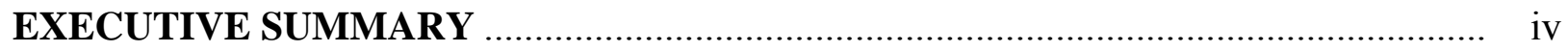

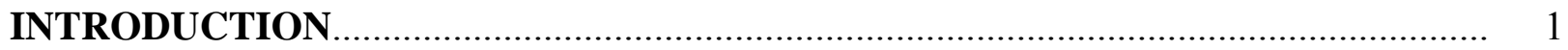

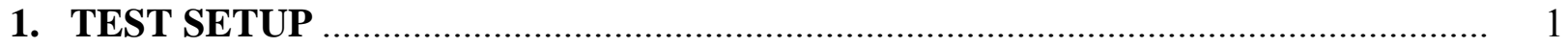

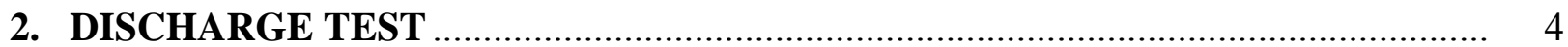

3. CORONA VOLTAGE TESTS ON MUSH-WOUND STATOR................................. 5

4. CORONA VOLTAGE TEST ON BOBBIN-WOUND STATOR ……....................... 8

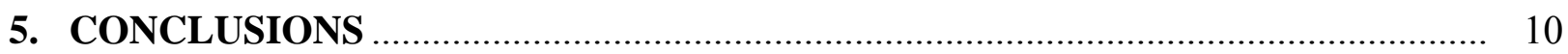

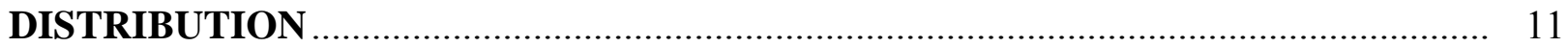




\section{FIGURES}

Figure

Page

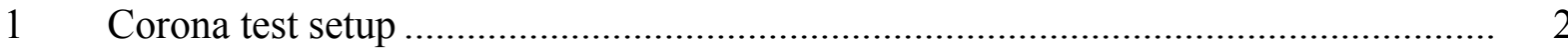

2 Current limiter and high-voltage transformer ................................................... 3

3 Clean trace from 0 to $9000 \mathrm{Vrms}$, (no corona), of test with silicone-sealed lead end

Test results of corona initiating at $9162 \mathrm{Vrms}$ with silicone-sealed lead end...........

$5 \quad$ Test setup produces discharge through 0.287-in. gap at $10076 \mathrm{Vrms}$ (temperature of $22.7^{\circ} \mathrm{C}$, humidity at $38.6 \%$ )

6 Corona discharging through 0.287 -in. gap at $10076 \mathrm{Vrms}$

7 Connection for mush-wound stator corona test.

8 Phase leads connected to ground for a combined phase-to-phase and phase-to-ground test

9 Corona initiating at 1638 Vrms for phase-to-phase and phase-to-ground test........... 7

10 Two (2) phase leads floating for a phase-to-ground test of a mush-wound stator ...... 7

11 Corona initiating at $2650 \mathrm{Vrms}$ for phase-to-ground test of a mush-wound stator..... 8

12 Bobbin-wound stator phase-to-ground corona test ........................................... 9

13 Corona initiating at 3176 Vrms for phase-to-ground test of bobbin-wound stator ..... 10

\section{TABLES}




\section{EXECUTIVE SUMMARY}

Electric power is equal to the product of voltage and current. For a given power, if a higher voltage and lower current are used, the size of the cable and the inverter switching components needed to carry the current can be reduced. The use of higher voltage also requires better and thicker electrical insulation that reduces the available slot area for motor windings. One mechanism of insulation breakdown is caused by corona that gradually erodes the insulation and shortens the life expectancy of motors.

For motors in electric vehicles (EVs) and hybrid electric vehicles (HEVs), the backelectromotive force (emf) at high speeds can be higher than the inverter output voltage, causing corona. High voltage spikes due to inverter switching can also be a source of corona.

To determine how high the voltage can be raised for EV and HEV applications, this investigation tests the voltage where corona initiates in a National Electrical Manufacturers Association mush-wound stator and an HEV bobbin-wound stator. Table 1 summarizes test results at $60 \mathrm{~Hz}$. The phase-to-phase corona initiates at only $1638 \mathrm{Vrms}$ for a mush-wound stator. The phase-to-ground (or frame) corona initiates higher at $2650 \mathrm{Vrms}$. The bobbin-wound stator shows slightly better performance than the mush-wound stator with a higher corona initiating voltage of 3176 Vrms.

Table 1. Summary of test results of corona

\begin{tabular}{|c|c|c|}
\hline Winding type & & Corona initiating voltage (Vrms) \\
\hline Mush-wound stator & Phase-to-frame & 2650 \\
\cline { 2 - 3 } & Phase-to-phase & 1638 \\
\hline Bobbin-wound stator & Phase-to-frame & 3176 \\
\hline
\end{tabular}




\section{INTRODUCTION}

It has been suggested that to meet the FreedomCAR objectives for cost, size, weight, efficiency, and reliability higher buss voltages be utilized in HEV and FC automotive applications. The reasoning is that since electric power is equal to the product of voltage and current for a given power a higher voltage and lower current would result in smaller cable and inverter switching components. Consequently, the system can be lighter and smaller. On the other hand, higher voltages are known to require better and thicker electrical insulation that reduce the available slot area for motor windings. One cause of slow insulation breakdown is corona that gradually erodes the insulation and shortens the life expectancy of the motor. This study reports on the results of a study on corona initiating voltages for mush-wound and bobbinwound stators. A unique testing method is illustrated.

\section{TEST SETUP}

Figure 1 shows the corona test setup. A neon transformer with $120-15000 \mathrm{~V}$ per side with the center tapped to ground was used to produce high voltages. Smooth sinusoidal utility power is supplied to the primary winding of the neon transformer through a $120-\mathrm{V}$ isolation transformer. An inductor coil wound on a ferrite core was used to sense the corona discharging current. The two terminals of the inductor coil are connected to ground and to the center tap of the high-voltage winding of the neon transformer. The oscilloscope input probes were connected across the inductor to pick up the corona discharging current signals. A current limiter was connected in series with the high-voltage output to protect the high-voltage winding from overcurrent from the neon transformer.

Silicone gel, silicone oil, or high-voltage putty were used to cover all exposed conductors at the non-grounded high-voltage side to prevent corona produced by the instrumentation setup. After the power to the setup was switched off, an insulated grounding pole was used to discharge any energy stored in the setup before its reconnection. High-voltage gloves and insulation pads were used for protection during the tests. 


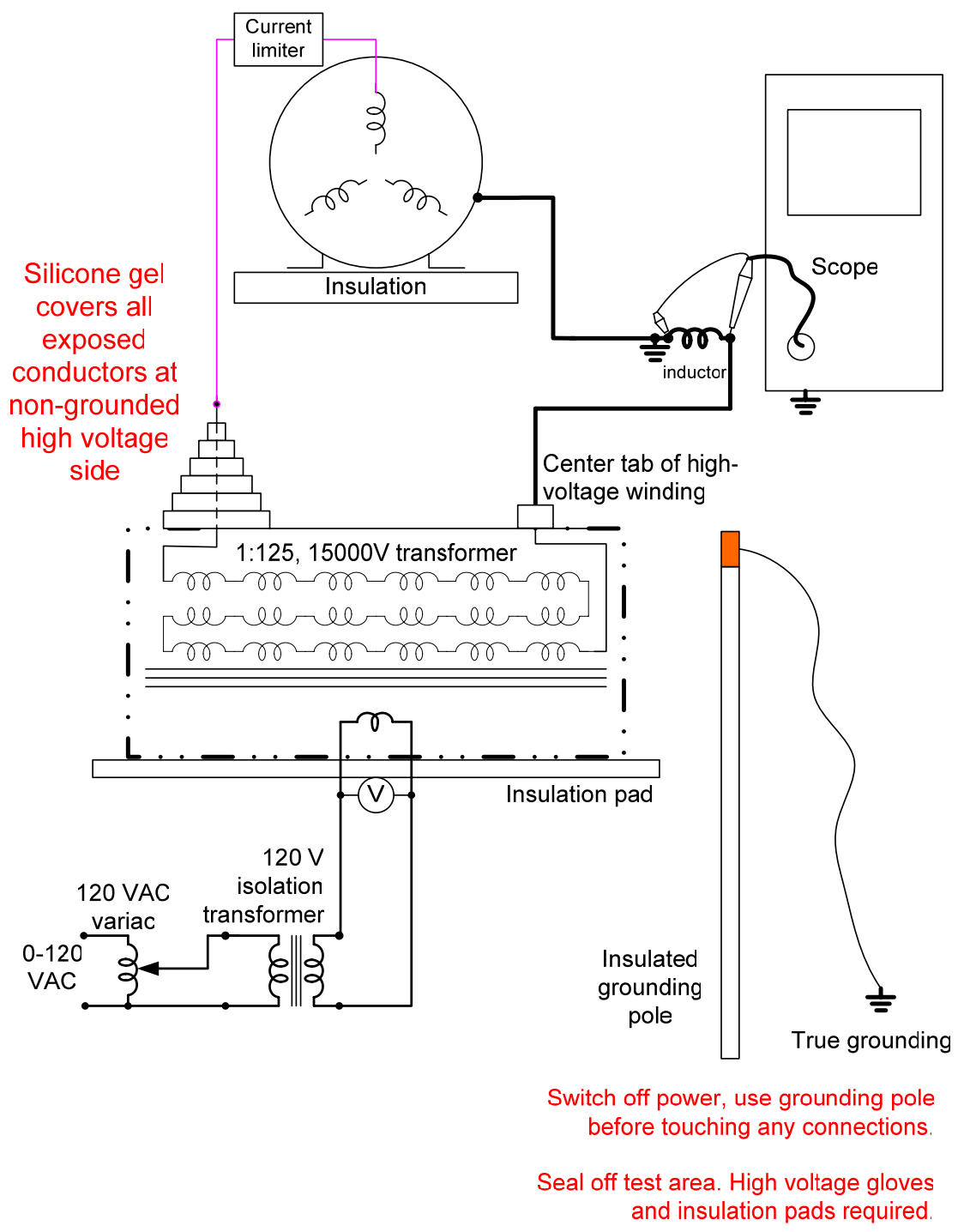

Fig. 1. Corona test setup.

Figure 2 shows the current limiter and its connection to the high-voltage transformer. The limiter was made of twenty $0.22-\mu \mathrm{F}, 600-\mathrm{Vdc}$ capacitors. Each capacitor was paralleled with a 1.24-M $\Omega, 1-\mathrm{W}$ resistor. Before corona occurs no discharging current exists in the circuit. The corona initiating voltage is not affected by the capacitors. Use of the capacitors for current limiting does not dampen the corona oscillations thus making corona detection more sensitive. The current limiter was submerged in silicone oil. 


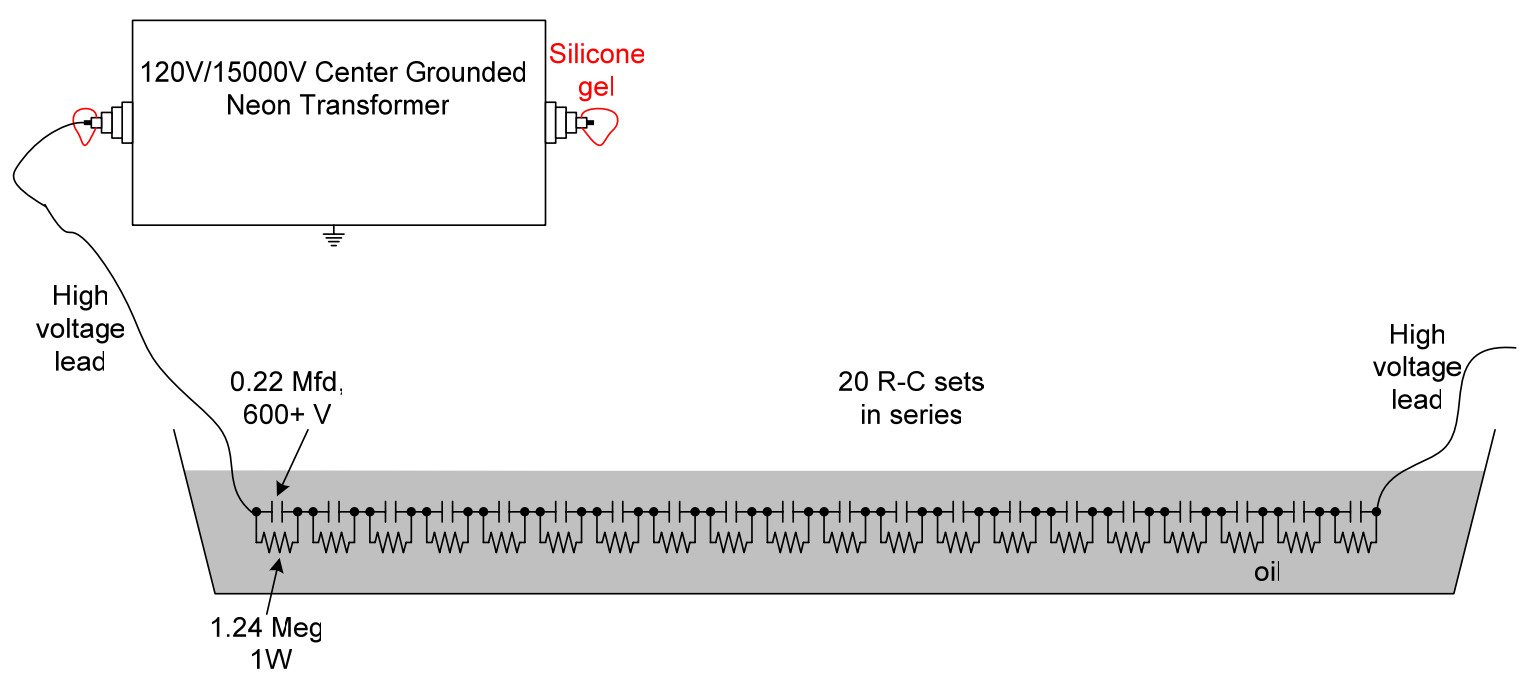

Fig. 2. Current limiter and high-voltage transformer.

In order to verify that the test setup did not produce a false corona signal before the highvoltage lead was connected to the motor, the high-voltage lead end was covered with a highvoltage putty. A clean trace, shown in Fig. 3, was observed while the high voltage was adjusted through the range of 0 to 9000 Vrms.

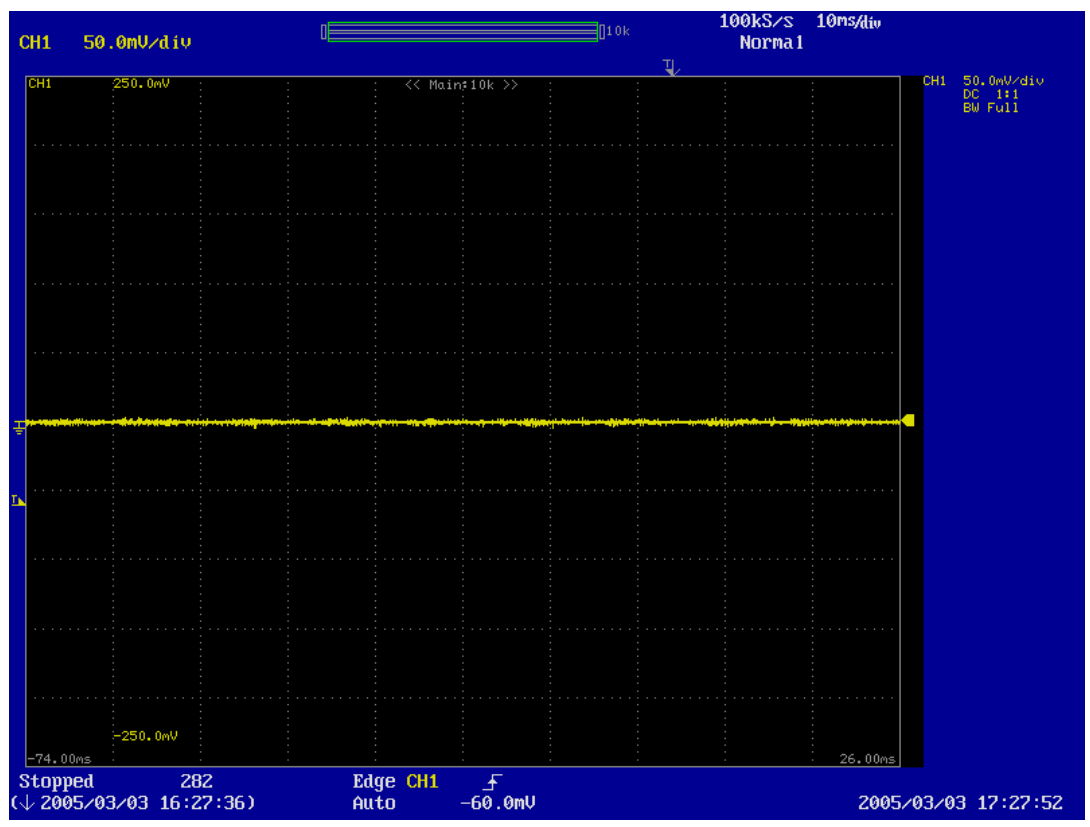

Fig. 3. Clean trace without corona from 0 to 9000 Vrms with silicone-sealed lead end.

Figure 4 shows the corona occurring in the test setup as the high voltage reached 9162 Vrms. 


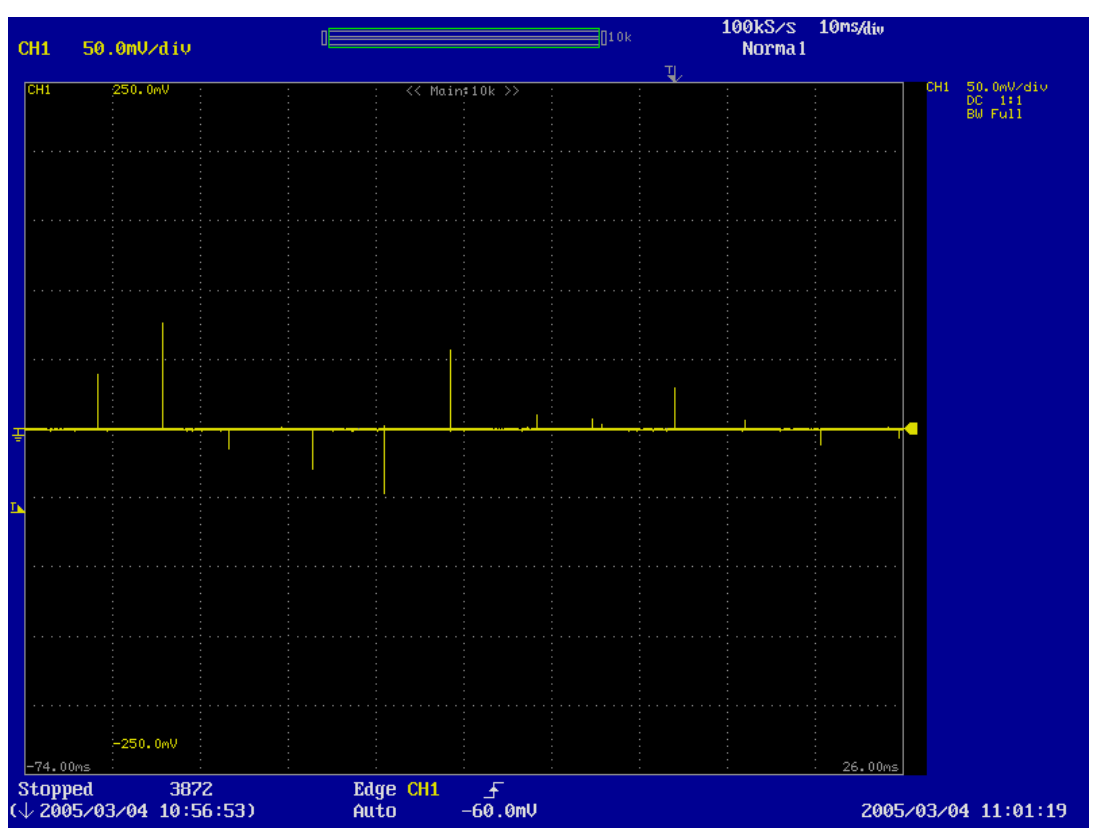

Fig. 4. Corona initiating in test setup at 9162 Vrms with silicone-sealed lead end.

\section{DISCHARGE TEST}

Figure 5(a) illustrates a 0.287-in. gap between the electrodes used in the discharge test. Corona discharges are seen in Fig. 5(b) taken with the use of a camera flash and in Fig. 5(c) without a camera flash. It was observed corona began when the high voltage reached 10076 Vrms. The test room temperature was $22.7^{\circ} \mathrm{C}$ and the humidity was $38.6 \%$. Significant corona traces are shown in Fig. 6.

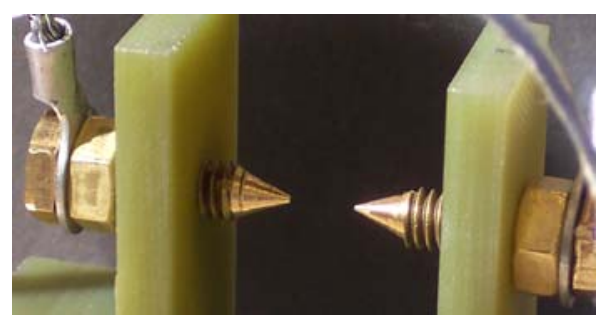

(a)

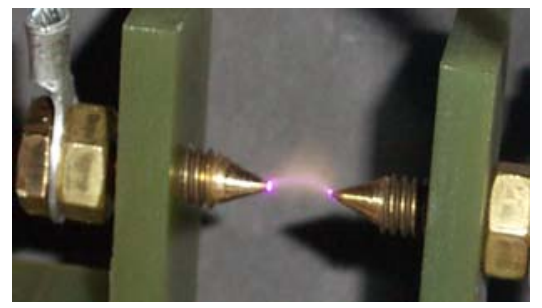

(b)

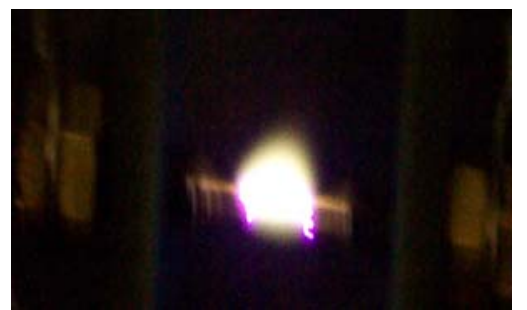

(c)

Fig. 5. Testing produces discharge through 0.287-in. gap at 10076 Vrms (temperature of $22.7^{\circ} \mathrm{C}$, humidity at $38.6 \%$ ). 


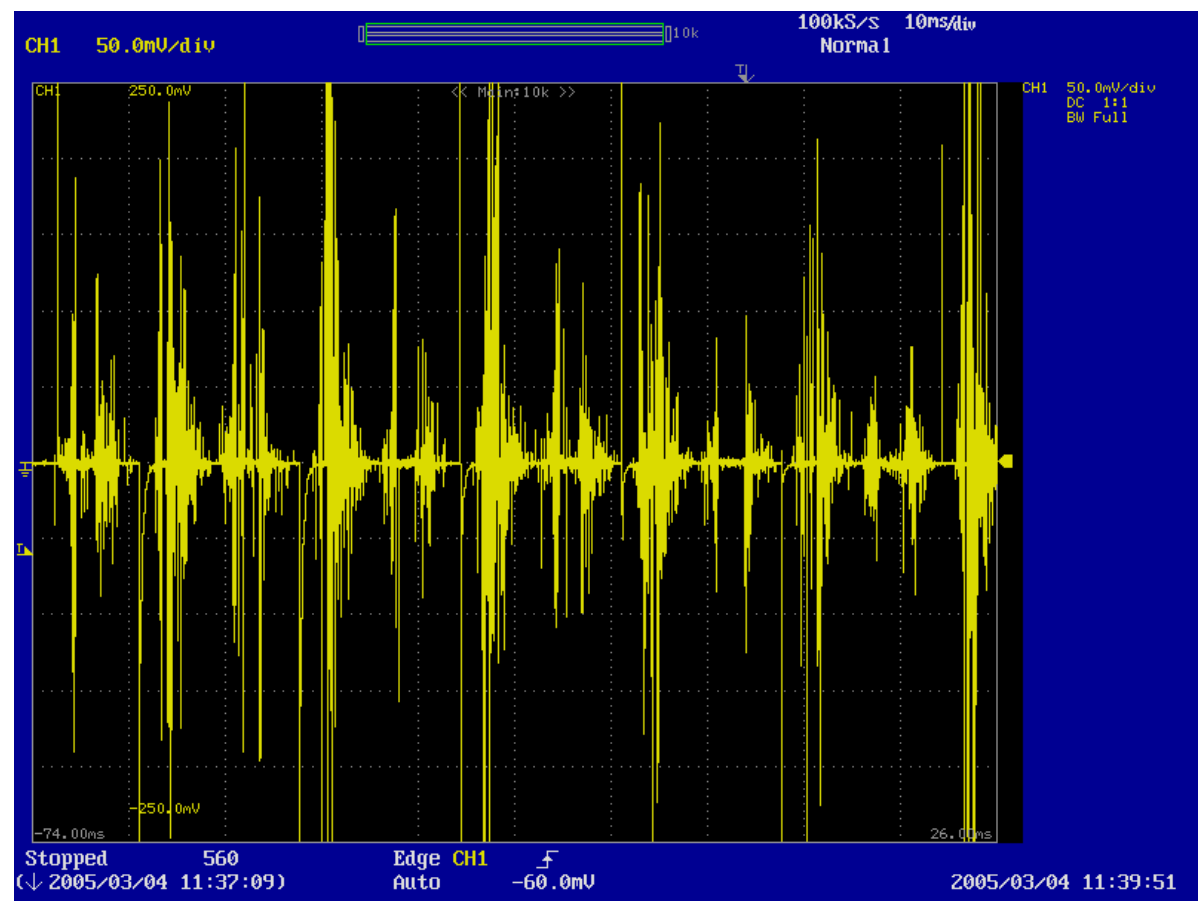

Fig. 6. Corona discharging through 0.287-in. gap at 10076 Vrms.

\section{CORONA VOLTAGE TESTS ON MUSH-WOUND STATOR}

Figure 7 shows the electrical connections made for the mush-wound stator corona test. The motor being tested is a 5-hp, 460-V, 3-phase, class-F insulation, 1.15 service-factor, 184-T frame, National Electrical Manufacturers Association design-A motor labeled "EPAct high efficient motor." This motor represents a typical $480-\mathrm{V}$ commercial motor. If the motor is fed by a sinusoidal pulse-width-modulated (PWM) inverter, the 480 -Vrms value corresponds to a $480 \cdot \sqrt{2}=679 \mathrm{dc}$ bus voltage. The high-voltage transformer, seen on the right side of the picture, has terminals sealed with silicone gel. The high-voltage transformer lead is connected to the capacitor current limiter submerged in silicone oil. The other end of the capacitor current limiter is connected to the motor lead and sealed with high-voltage putty. The inductor used to sense the corona oscillation current signal is shown on top of the motor. 


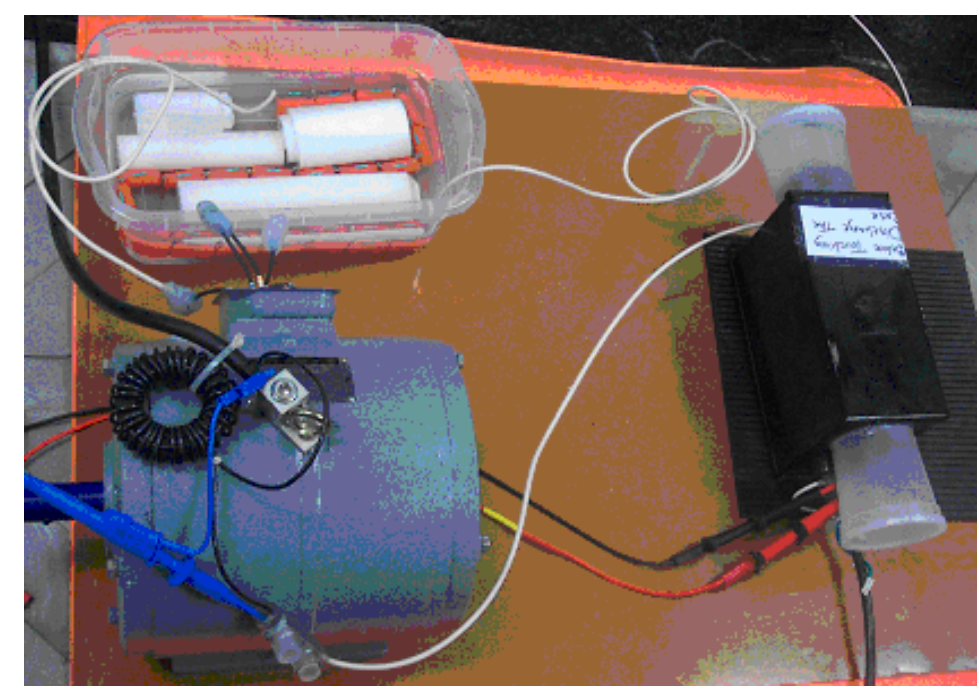

Fig. 7. Connection for mush-wound stator corona test.

Figure 8 shows the electrical connections for the phase-to-phase and phase-to-ground corona tests. Phase leads were connected to ground to create a potential difference between the targeted phase and the other phases. The leads of the targeted phase are sealed with silicone gel to prevent any corona produced by the bare copper.

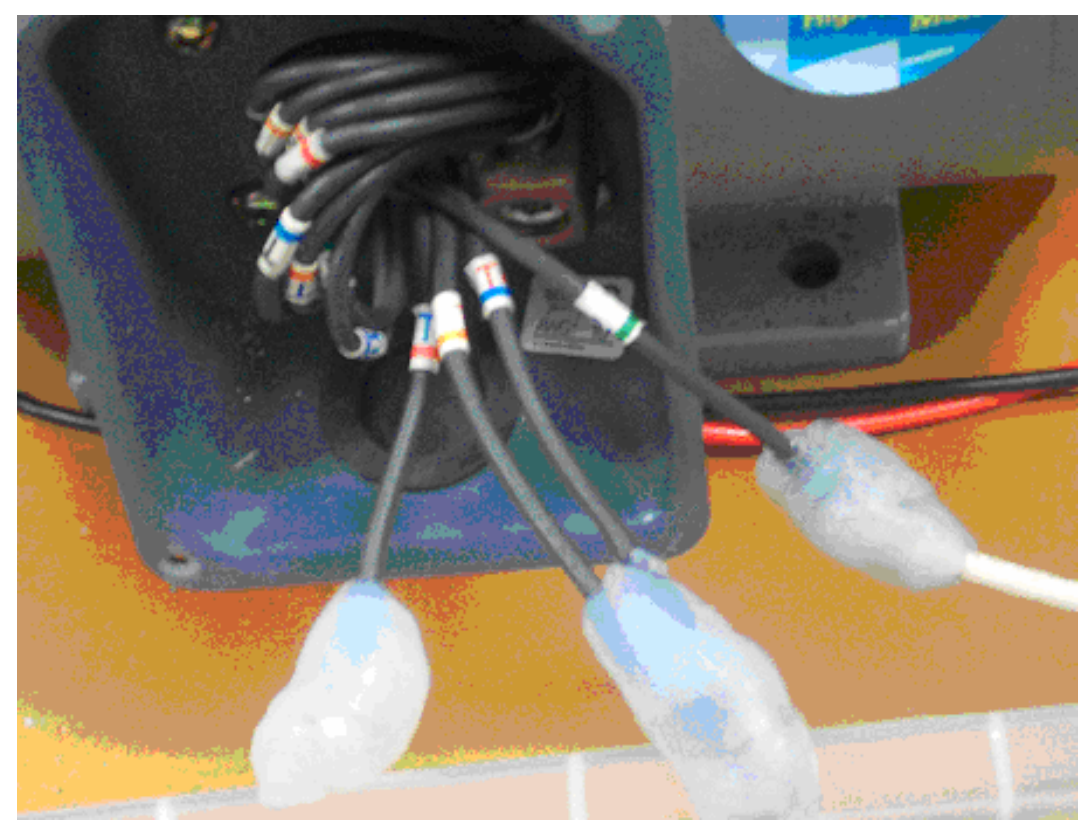

Fig. 8. Phase leads connected to ground for a combined phase-to-phase and phase-to-ground test.

Figure 9 shows that corona initiates at 1638 Vrms for the phase-to-phase windings and phase-to-ground tests on a 460-Vrms mush-wound stator. 


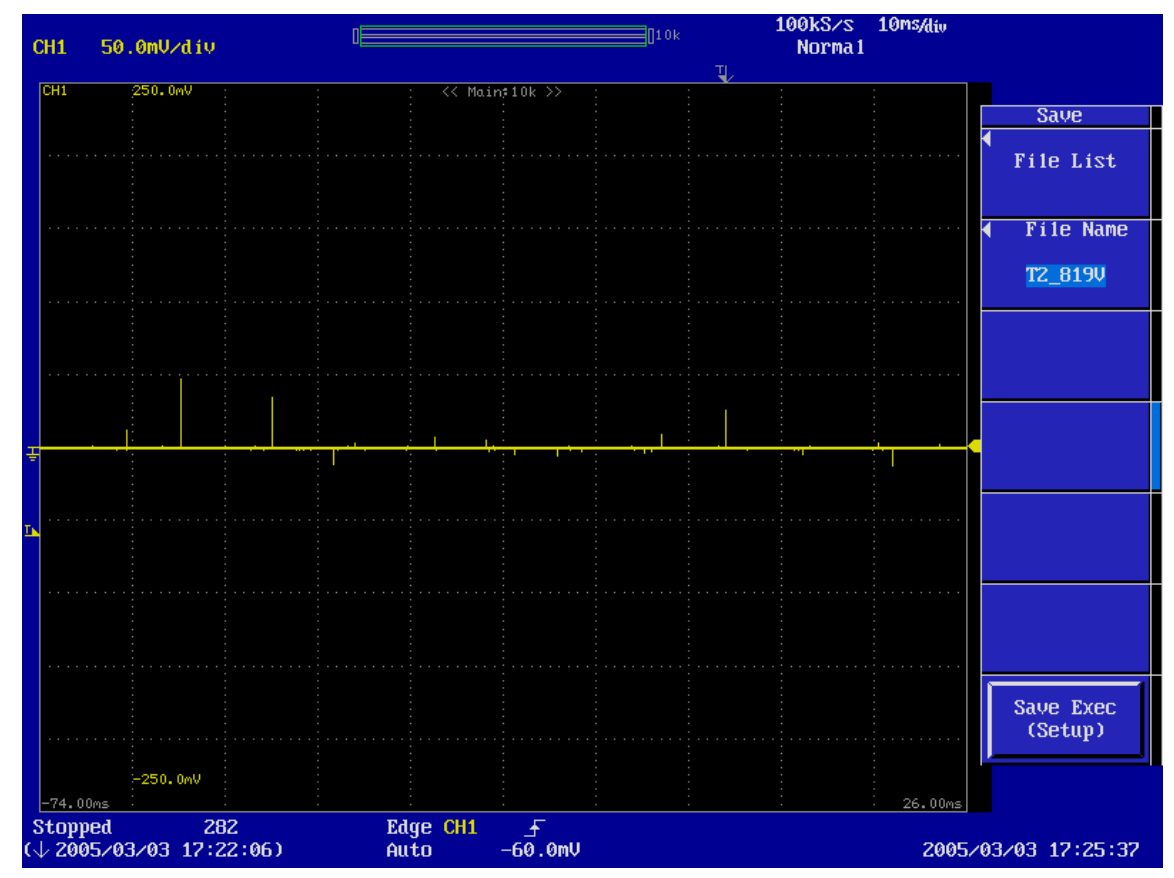

Fig. 9. Corona initiating at 1638 Vrms for phase-to-phase and phase-to-ground test.

Figure 10 shows that for the phase-to-ground corona test, the other phase leads are not connected to ground. The potentials of the other phases are floating since there is no connection to any source. The leads of the targeted phase are sealed with high-voltage putty to prevent any corona from being produced by the bare copper.

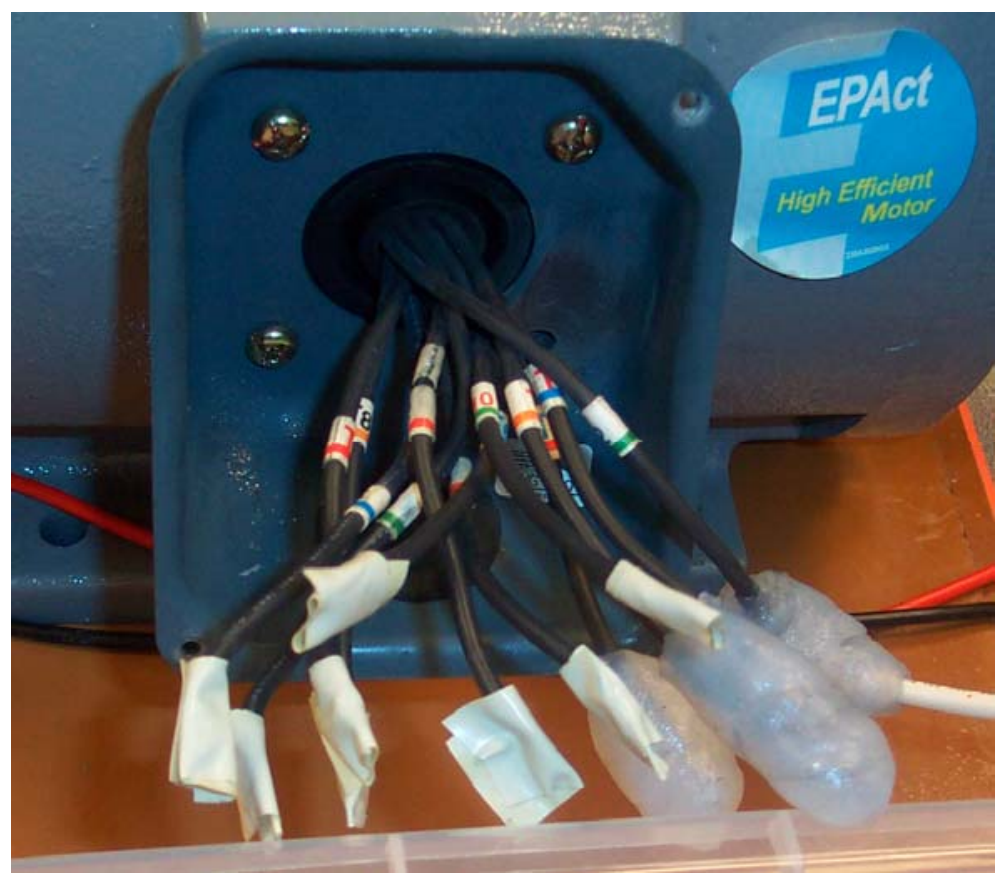

Fig. 10. Two (2) phase leads floating for a phase-to-ground test of a mush-wound stator. 
Figure 11 shows that corona begins at 2650 Vrms for the phase-to-ground test on a 460-Vrms mush-wound stator.

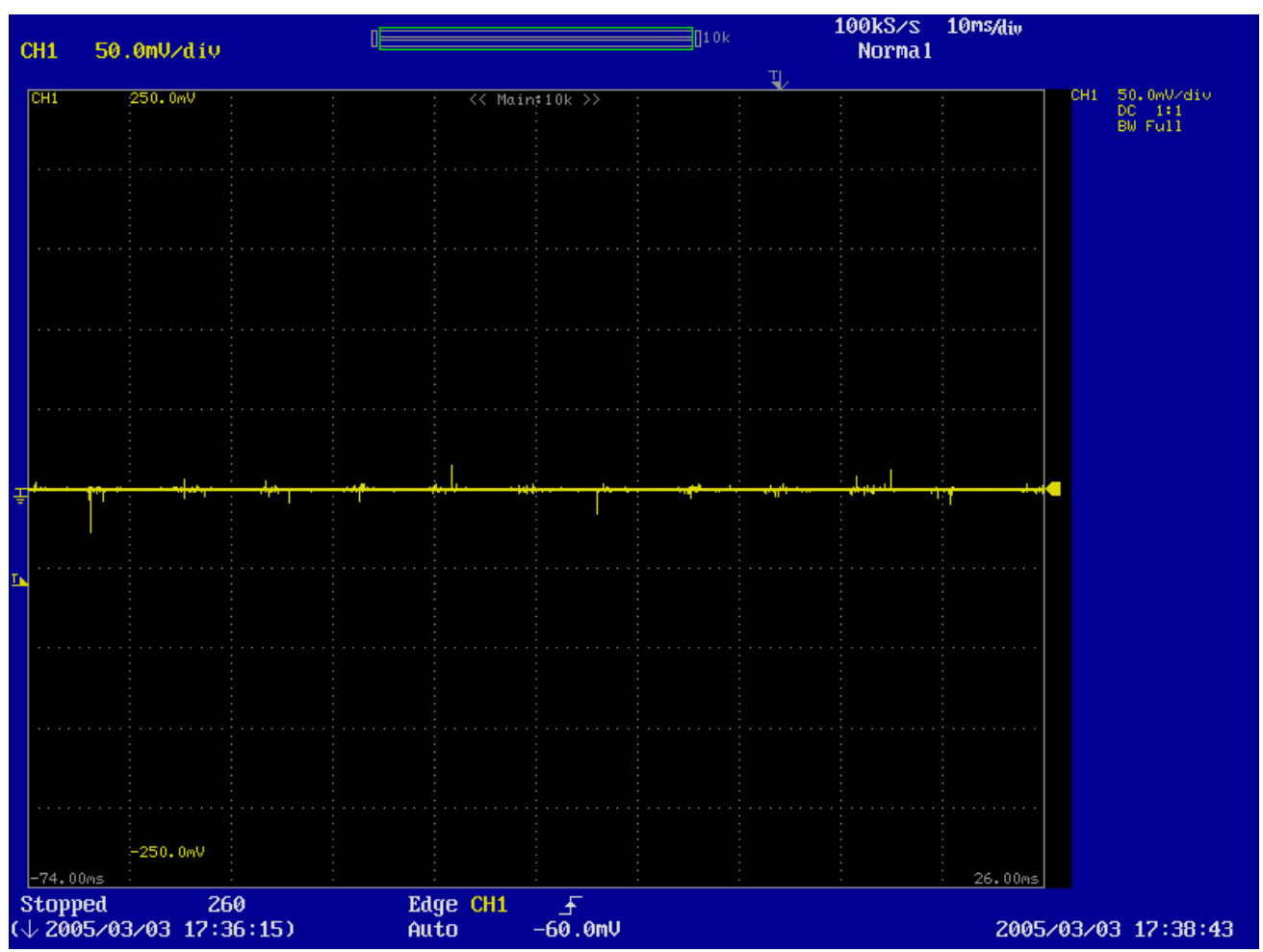

Fig. 11. Corona initiating at 2650 Vrms for phase-to-ground test of a mush-wound stator.

\section{CORONA VOLTAGE TEST ON BOBBIN-WOUND STATOR}

Figure 12 shows the corona test on an HEV bobbin-wound stator. Unlike a mush-wound stator, there is no other phase coil laid directly on top of a phase coil for the bobbin-wound stator. Therefore, the phase-to-phase insulation is not a major concern. 


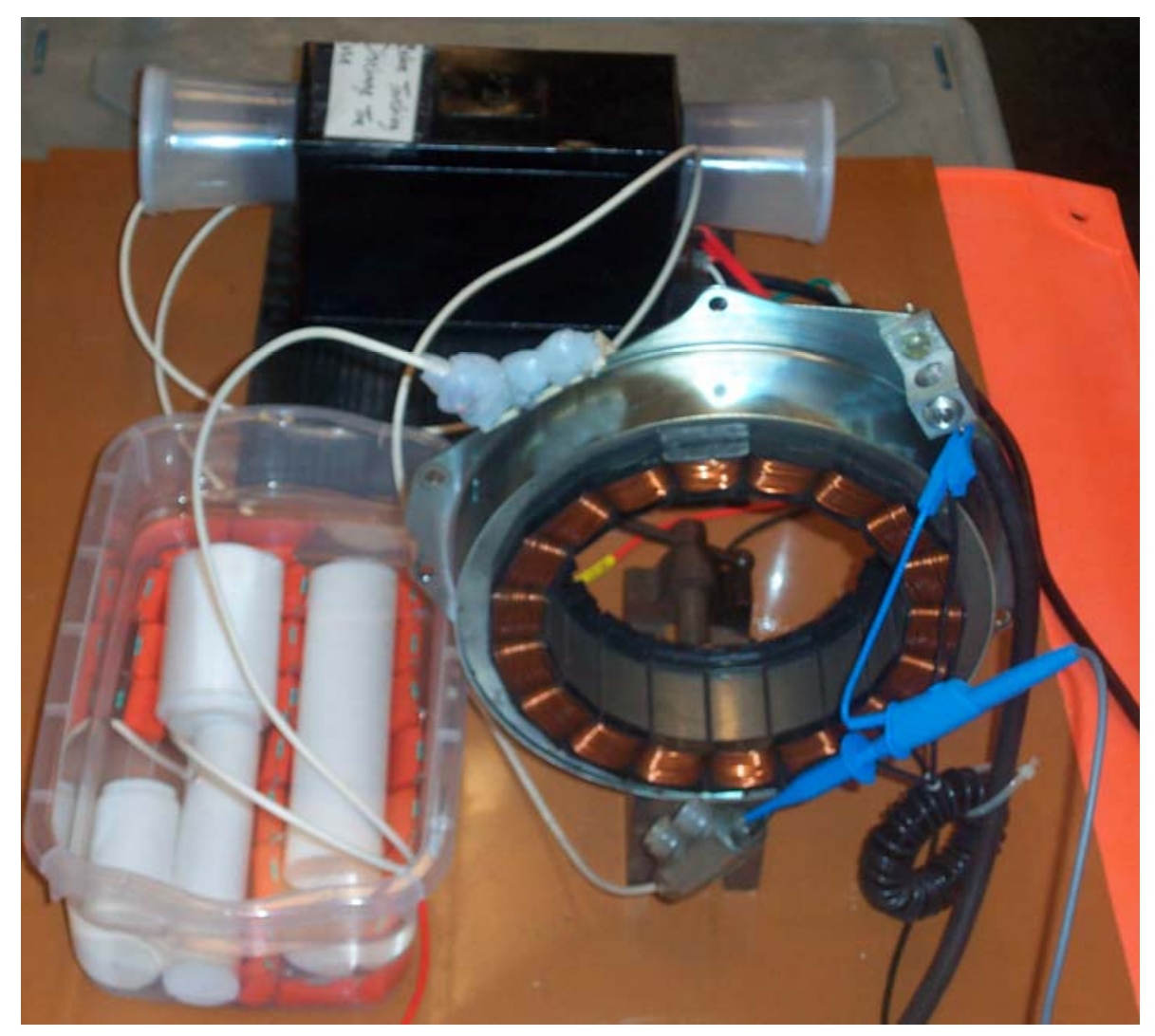

Fig. 12. Bobbin-wound stator phase-to-ground corona test.

For all motors, there is an insulation issue between turns. For 460 Vrms motor, the turn-toturn insulation is dependent upon the magnet-wire coatings, which are available in different temperature ratings. Because the bobbin coil can be systematically wound, the first turn never touches the last turn in a coil. The turn-to-turn voltage stress is less than that of mush-wound coils.

It is no surprise that the phase-to-ground corona of a bobbin-wound stator, initiating at $3176 \mathrm{Vrms}$, is higher than that of a mush-wound stator (1638 Vrms phase-to-phase and 2650 Vrms phase-to-ground), as shown in Fig. 13. 


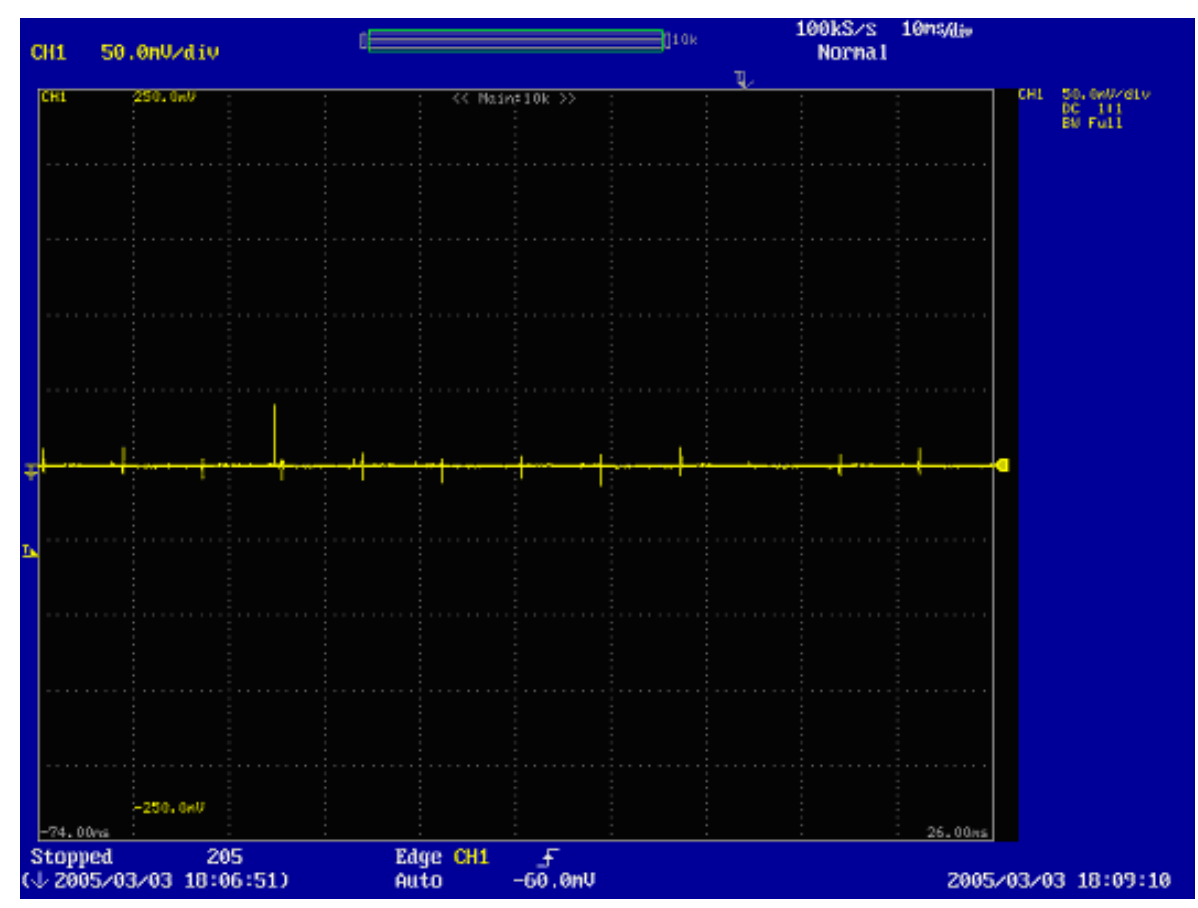

Fig. 13. Corona initiating at 3176 Vrms for phase-to-ground test of bobbin-wound stator.

\section{CONCLUSIONS}

This study addresses the question of how high the voltage can be raised for the operation of electric motors. Two common motors, the mush-wound motor with overlapping phase windings and the bobbin-wound motor without overlapping phase windings, were tested. A unique corona detector, developed at ORNL, was used to measure the voltage where corona initiates in the two motors.

Table 1 in the Executive Summary summarizes test results at $60 \mathrm{~Hz}$.

The conclusions given in this report were obtained through tests using a sinusoidal voltage without any voltage spikes. In practice, motors fed by inverters will generate significant voltage spikes that must be taken into consideration. The fundamental voltage values of the motors tested for corona-free operation must be lower than the corona initiating sinusoidal voltages given in this report. How much lower depends on the output voltage quality of the inverter.

In conclusion, the dc-bus voltage, the magnitude of the back-emf, the insulation, winding space, and the voltage where corona begins must all be considered in determining the voltage level and voltage-related issues of EV and HEV inverters and motors. 


\section{DISTRIBUTION}

$\underline{\text { Internal }}$

1. D. J. Adams

2. S. L. Campbell

3. C. L. Coomer

4. E. C. Fox

5. J. S. Hsu

6. K. P. Gambrell
7. L. D. Marlino

8. J. W. McKeever

9. J. Miller

10. M. Olszewski

11-12. Laboratory Records

$\underline{\text { External }}$

13. T. Q. Duong, U.S. Department of Energy, EE-2G/Forrestal Building, 1000 Independence Avenue, S.W., Washington, D.C. 20585.

14. R. R. Fessler, BIZTEK Consulting, Inc., 820 Roslyn Place, Evanston, Illinois 60201-1724.

15. K. Fiegenschuh, Ford Motor Company, Scientific Research Laboratory, 2101 Village Road, MD-2247, Dearborn, Michigan 48121.

16. V. Garg, Ford Motor Company, 15050 Commerce Drive, North, Dearborn, Michigan 48120-1261.

17. E. Jih, Ford Motor Company, Scientific Research Laboratory, 2101 Village Road, MD1170, Rm. 2331, Dearborn, Michigan 48121.

18. W. C. Johnson, University of Tennessee-Knoxville, ECE Department, 414 Ferris Hall, 1508 Middle Drive, Knoxville, Tennessee 37996.

19. A. Lee, Daimler Chrysler, CIMS 484-08-06, 800 Chrysler Drive, Auburn Hills, Michigan 48326-2757.

20. F. Liang, Ford Motor Company, Scientific Research Laboratory, 2101 Village Road, MD1170, Rm. 2331/SRL, Dearborn, Michigan 48121.

21. M. W. Lloyd, Energetics, Inc., 7164 Columbia Gateway Drive, Columbia, Maryland 21046.

22. Brenda Medellon, USCAR, brenda@uscar.org

23. M. Mehall, Ford Motor Company, Scientific Research Laboratory, 2101 Village Road, MD-2247, Rm. 3317, Dearborn, Michigan 48124-2053.

24. J. Rogers, Chemical and Environmental Sciences Laboratory, GM R\&D Center, 30500 Mound Road, Warren, Michigan 48090-9055.

25. S. A. Rogers, U.S. Department of Energy, EE-2G/Forrestal Building, 1000 Independence Avenue, S.W., Washington, D.C. 20585.

26. G. S. Smith, General Motors Advanced Technology Center, 3050 Lomita Boulevard, Torrance, California 90505.

27. E. J. Wall, U.S. Department of Energy, EE-2G/Forrestal Building, 1000 Independence Avenue, S.W., Washington, D.C. 20585.

28. B. Welchko, General Motors Advanced Technology Center, 3050 Lomita Boulevard, Torrance, California 90505.

29. P. G. Yoshida, U.S. Department of Energy, EE-2G/Forrestal Building, 1000 Independence Avenue, S.W., Washington, D.C. 20585. 